\title{
In vitro analysis of the cytotoxicity and the antimicrobial effect of four endodontic sealers
}

\author{
Ines Willershausen, Angelika Callaway, Benjamin Briseño and Brita Willershausen*
}

\begin{abstract}
Introduction: The aim of this study was to investigate in vitro the cytotoxicity and antibacterial properties of four different endodontic sealers using human periodontal ligament fibroblast cell proliferation and visual analysis of growth inhibition.

Methods: A silicone (GuttaFlow), silicate (EndoSequence BC), zinc oxide eugenol (Pulp Canal Sealer EWT) and epoxy resin (AH Plus Jet) based sealer were incubated with PDL fibroblasts $\left(10^{4}\right.$ cells $\left./ \mathrm{ml}, \mathrm{n}=6\right)$ up to $96 \mathrm{~h}$. Cell proliferation (RFU) was determined by means of the Alamar Blue assay. Cell growth and morphology was visualized by means of fluorescent dyes. Possible antibacterial properties of the different sealers were visualized by means of SEM (Enterococcus faecalis; Parvimonas micra).

Results: Fibroblast proliferation depended on sealer and cultivation time. After 72 and 96 h GuttaFlow and EndoSequence BC showed relatively non-cytotoxic reactions, while Pulp Canal Sealer EWT and AH Plus Jet caused a significant decrease of cell proliferation $(p<0.001)$. Visualization of cell growth and morphology with various fluorescent dyes supplemented the results. No antibacterial effect of EndoSequence BC to P. micra was found, whereas GuttaFlow showed a weak, Pulp Canal Sealer EWT and AH Plus Jet extensive growth inhibition. Also, no antibacterial effect of GuttaFlow, EndoSequence BC or AH Plus Jet to E. faecalis could be detected.
\end{abstract}

Conclusions: These in vitro findings reveal that GuttaFlow and EndoSequence BC can be considered as biocompatible sealing materials. However, prior to their clinical employment, studies regarding their sealing properties also need to be considered.

Keywords: in vitro study, root canal sealer, E. faecalis P. micra, cytotoxicity

\section{Introduction}

In recent decades, a considerable Improvement in endodontic methods, devices, and also in root canal filling materials, has occurred. Thus, patients as well as dental professionals are more inclined to favour tooth preservation over extraction of disputable teeth $[1,2]$. In consequence, since increased technical knowledge and scientific improvements have lead to higher treatment success rates, endodontic treatment and the subsequent restoration of the tooth should be considered as a therapy superior to implantation $[3,4]$.

The choice of a biocompatible sealing material is crucial to the clinical success of endodontic therapy [5]. Although sealers were developed to be confined within

\footnotetext{
* Correspondence: brita.willershausen@unimedizin-mainz.de Department of Operative Dentistry, University Medical Centre of the Johannes Gutenberg University Mainz, Germany
}

the root canal system, their extrusion over the apical constriction is frequently observed [6,7]. Therefore, these materials should have good biocompatibility and be well tolerated by the peri-apical tissues [8]. The induction of a mild tissue reaction, together with cellular resorption of the sealing material in the case of extrusion over the apical foramen, needs to be evaluated. Several in vitro, in vivo and clinical studies [9-13] indicate that $\mathrm{AH}$ Plus, an epoxy resin-based root canal sealer, is suitable for successful endodontic therapy. This sealer remains popular despite its well-documented mutagenicity [14], cytotoxicity and the induction of a severe inflammatory response [15-17]. Besides cell dysfunctionality as a reaction to the epoxy resin-based sealing material [16], an intense inflammation characterized by the presence of lymphocytes, macrophages, giant foreign body cells as well as necrotic bone fragments in

\section{(Ciomed Central}


maxilla of guinea pigs after AH Plus implantation was observed. Due to its severe initial inflammatory reaction that diminished over time but persisted throughout the entire observation period, the authors [17] claim that this material does not possess enough biocompatible properties to be considered as an acceptable sealer for clinical use. Based on these contradictory results concerning an endodontic sealing material with a "gold standard" status [13], the tissue reaction induced by alternative sealers needs to be investigated in similar study designs to decide upon their potential clinical usage. GuttaFlow is a relatively new sealing material, which combines gutta-percha and sealer into an injectable system. According to the manufacturer, this system is based on polydimethylsiloxane with added guttapercha and nano-silver particles $(<30 \mu \mathrm{m})$. Due to its viscosity, it is more likely to be extruded into the periapical tissue when placed under pressure [18]. However, it remains unclear which tissue reaction is caused by this material. In the study of AlAnezi et al. [19], the possible cytotoxicity of Endosequence BC Root Repair Material and grey and white MTA was evaluated. When exposed to these materials, the cells showed no significant difference in viability, while the cells in contact with AH 26 were significantly reduce in their viability.

Cleaning and shaping procedures are used to eliminate microorganisms from the root canal system during endodontic treatment. However, quite often a complete removal of bacteria is not possible [20]. In such cases it would be desirable that sealing materials have antimicrobial properties. Using either the agar diffusion test or the direct contact test or both, different endodontic sealers have already been assessed for a possible antibacterial effect, most often measured against strains of E. faecalis [21-28].

Baer and Maki [29] demonstrated that AH Plus and Pulp Canal Sealer EWT were not able to inhibit the growth of E. faecalis.

Therefore, the present in vitro study aimed at comparing the biocompatibility and the possible antibacterial effect on E. faecalis and P. micra of the four different root filling materials GuttaFlow, Endosequence BC, Pulp Canal Sealer EWT and AH Plus Jet.

\section{Materials and methods}

\section{Sealing materials}

For this in vitro study four different root canal sealers were chosen: GuttaFlow (Roeko, Coltène Langenau Germany, Batch No. 240412) consists of a polydimethylsiloxane matrix, is a cold flowable and self-curing sealer, which combines sealer and gutta-percha in one product; Endosequence BC Sealer (Brasseler, Savannah, GA, USA, Batch No. 0900458) is a premixed ready-to-use injectable material, based on a calcium silicate composition; Pulp Canal Sealer EWT (Pulp Canal Sealer EWT; SybronEndo, Orange, CA, USA, Batch No. 9-1222) is a zinc oxide eugenol based sealer; AH Plus Jet (Dentsply/Detrey, Konstanz, Germany, Batch No. 1004002041) is an epoxy resin based root canal sealer and consists of a paste-paste system, with paste A containing epoxy resin and iron oxide, and paste B containing amines and silicone oil.

The sealers were prepared according to the manufacturers' recommendations. For the cell culture experiments, the materials $(1.3 \mathrm{mg} \pm 0.1 \mathrm{mg})$ were placed at the junction between the base and wall of each multiwell cylinder (16 mm diameter; Greiner Bio-One, Frickenhausen, Germany), thus covering only a small area of the well. The amount of sealer was determined according to preliminary experiments and calculated by weighing the sealers with an analytical balance (Pioneer PA64, Ohaus, Pine Brook, USA, Figure 1, left). The sealing materials were allowed to set for $24 \mathrm{~h}$.

To determine the bacterial colonization of root canal sealers, discs of equal size $(\varnothing 12.5 \pm 0.5 \mathrm{~mm}$; thickness $2 \pm 0.5 \mathrm{~mm}$ ) were prepared under sterile conditions from the materials and allowed to set for $24 \mathrm{~h}$.

\section{Cell culture}

Human Periodontal Ligament Fibroblasts (Clonetics ${ }^{\circledR}$ HPdLF Lonza, Switzerland) were cultured in Dulbecco's

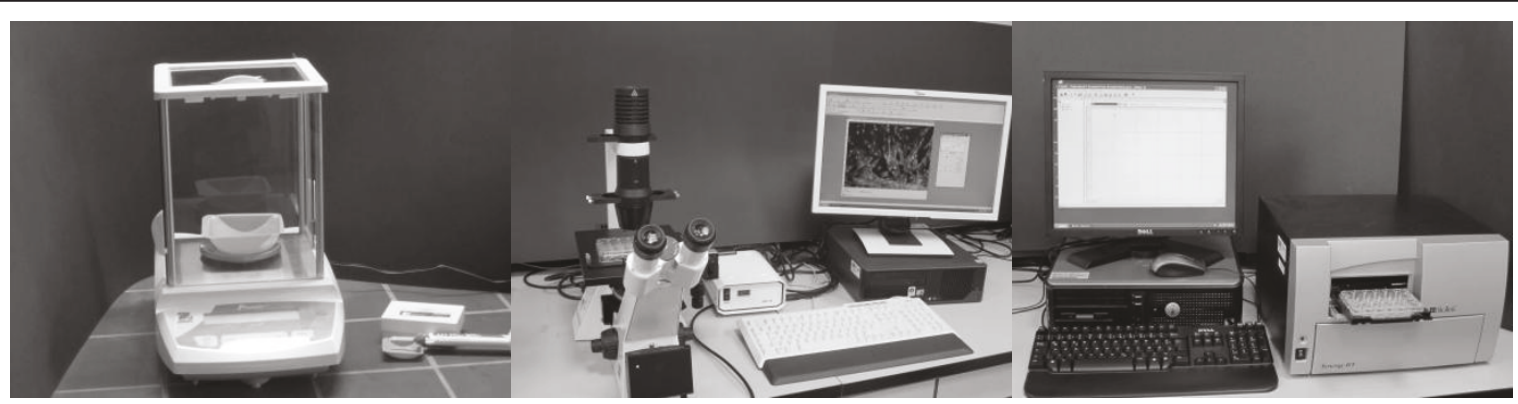

Figure 1 Analytical balance (Pioneer PA64, Ohaus, Pine Brook, USA), left; inverted fluorescence microscope (Axiovert 40C/Carl Zeiss, Göttingen, Germany), middle; fluorescence/luminescence reader (Synergy HT-Reader, Biotek, Winooski, VT, USA), right. 
Modified Eagle Medium, supplemented with 10\% foetal bovine serum, $2 \mathrm{mM}$ L-Glutamine and 100U/100 $\mu \mathrm{g} / \mathrm{ml}$ Penicillin/Streptomycin (Invitrogen, Paisley, UK), incubated at $37^{\circ} \mathrm{C}$, in a humidified atmosphere containing $5 \% \mathrm{CO}_{2}$, and a bidaily medium change. To assess the interaction of the sealing agents with the fibroblasts, different in vitro assays were carried out.

\section{Cell fluorescence}

To demonstrate the interactions between cells and sealing materials, cells $(20,000$ cells/well) were stained with various fluorescent dyes and viewed with an inverted fluorescence microscope (Axiovert 40C/Carl Zeiss, Göttingen, Germany) at magnifications of $\times$ 25-400 (Figure 1, middle).

Phallacidin (BODIPY ${ }^{\circledR}$ FL phallacidin; Invitrogen, Paisley, UK) selectively labels F-actin and was used to visualize the cytoskeleton. The blue-fluorescent DAPI nucleic acid stain (4',6-Diamidine-2'-phenylindole dihydrochloride; Roche Diagnostics, Mannheim, Germany) preferentially stains double stranded DNA. It yields highly fluorescent nuclei and no detectable cytoplasmic fluorescence. Blue fluorescence contrasts vividly with the green phallacidin staining.

Calcein-AM/Ethidium homodimer II staining (LIVE/ DEAD $^{\circledR}$ Viability/Cytotoxicity Kit; Invitrogen, Paisley, UK), a two-colour fluorescence-based method, was used to measure the viability of the cultured cells, and to detect a possible cytotoxic effect of the sealers. Calcein $\mathrm{AM}$ is a fluorogenic esterase substrate that is hydrolysed intracellularly to a green fluorescent product, which is an indicator of live cells. Ethidium homodimer II enters cells through damaged membranes and intercalates with the DNA in the nucleus, emitting a red fluorescent signal.

\section{Cell viability assays}

The four sealers were tested for possible effects on cell proliferation and metabolic activity of the PDL fibroblasts. Cell proliferation was quantitatively measured by means of the Alamar Blue assay (Alamar Blue Cell Viability Reagent; Biozol, Eching, Germany), which is based on detection of metabolic cell activity. The Alamar Blue reagent contains an indicator dye, which fluoresces in response to cell growth. The cells were incubated in a 96-well plate $(10,000$ cells/well) under standard conditions, and with 10\% Alamar Blue for 96 h. At $0,1,6,24,48,72,96 \mathrm{~h}$ the fluorescence was measured at a wavelength of $560 / 20$ and $620 / 40 \mathrm{~nm}$ with a fluorescence reader (Synergy HT-Reader, Biotek, Winooski, VT, USA). Cells without sealing material served as control. Logarithmic signals were converted to a linear scale and expressed as relative fluorescence units (RFU).
The cytotoxic potential of the four sealing materials was also investigated by means of the ToxiLight ${ }^{\circledR}$ BioAssay Kit (Lonza Rockland, Rockland, ME, USA). This assay is a non-destructive, bioluminescent cytotoxicity assay, which quantitatively measures the release of Adenylate Kinase (AK) from damaged cells. The PDL fibroblasts were incubated under standard conditions in a 96well plate (30,000 cells/well). After incubating the cells with the sealing agent for $24 \mathrm{~h}$, the supernatants were mixed with AK detection agent. After 5 min incubation, the emitted light intensity is measured in a luminometer (Synergy HT-Reader, Biotek, Winooski, VT, USA, Figure 1, right). Logarithmic signals were converted to a linear scale and expressed as relative luminescence units (RLU).

\section{Bacterial colonization of root canal sealers}

Enterococcus faecalis DSM 20478 was grown anaerobically for $24 \mathrm{~h}$ at $37^{\circ} \mathrm{C}$ in Schaedler broth (Becton Dickinson, Sparks, MD, USA). Parvimonas micra ATCC 33270 was grown anaerobically for $48 \mathrm{~h}$ at $37^{\circ} \mathrm{C}$ in Anaerobe Basal Broth (Oxoid, Basingstoke, Hampshire, England). Discs of equal size, prepared from the cements and set, were placed into Petri dishes, containing $25 \mathrm{ml}$ of nutrient broth, inoculated with E. faecalis or $P$. micra, and incubated anaerobically at $37^{\circ} \mathrm{C}$. After $24 \mathrm{~h}$ (E. faecalis) or $48 \mathrm{~h}$ ( $P$. micra) of incubation, the discs were removed. To make the bacteria visible in a scanning electron microscope (SEM), the samples were fixed for $30 \mathrm{~min}$ in $3 \%$ formaldehyde at room temperature, and dehydrated by sequential washes through a series of 50 to $96 \%$ graded ethanol baths. After sputtering in a cold sputter unit, the samples were viewed in a DSM 962 SEM (Zeiss, Oberkochen, Germany) at an accelerating voltage of $10 \mathrm{kV}$.

\section{Statistical analysis}

Six replicates per sealing material were used in the cell proliferation and cytotoxicity assays, and the results are presented as means \pm standard deviation. The statistical analysis was performed using SPSS 15.0 (SPSS Inc., Chicago, IL) and SAS 9.2 (SAS Institute Inc., Cary, NC). The data were analysed by the Mann-Whitney-Test; p < 0.05 was chosen to define statistical significance, $\mathrm{p}<$ 0.01 was termed as highly significant.

\section{Results}

The Alamar Blue assay yields information about the proliferation rate of the PDL fibroblasts incubated with the different sealers over a period of $96 \mathrm{~h}$. In this assay, high cellular proliferation rates were expressed as high relative fluorescence units (RFU). The here-investigated sealers influenced the proliferation and viability of the human periodontal ligament fibroblasts in different degrees (Figure 2). After an incubation time of $24 \mathrm{~h}$, 


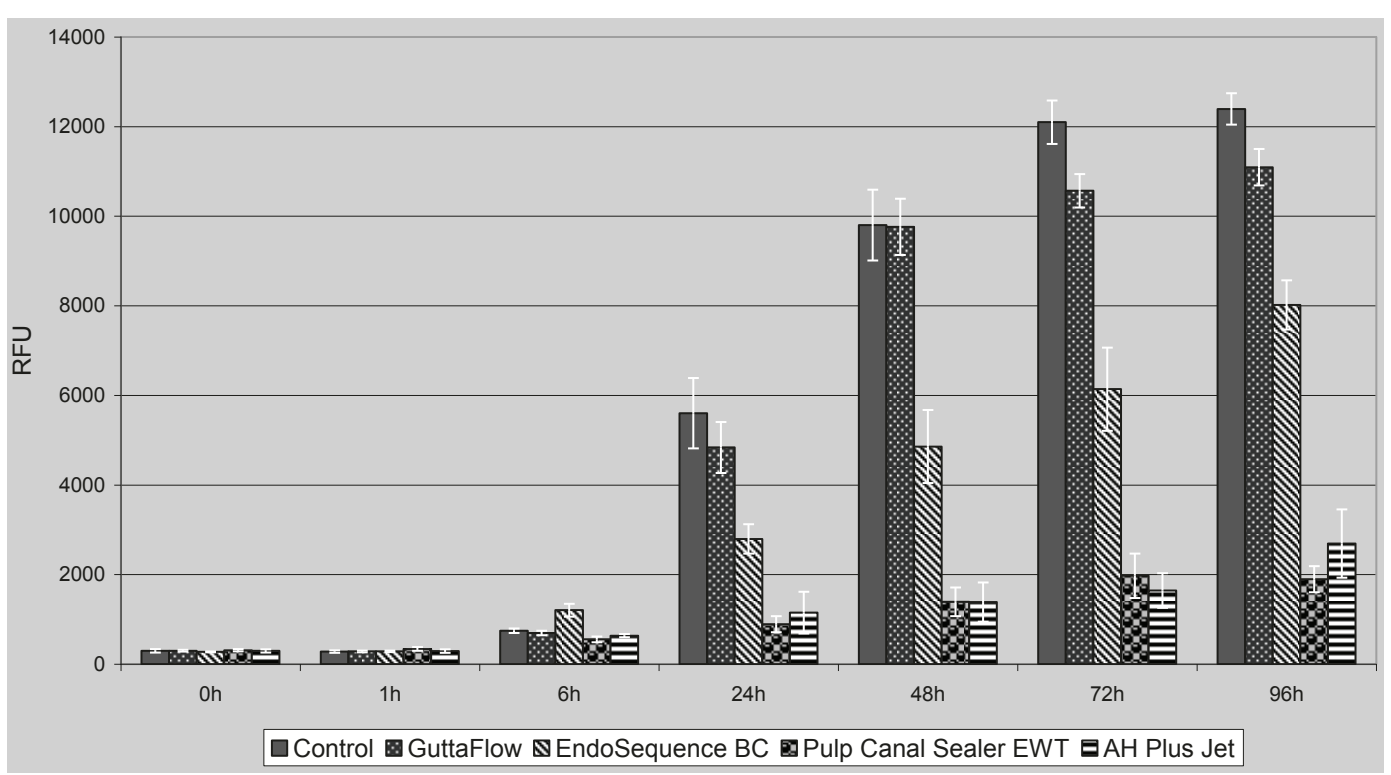

Figure 2 Results of the Alamar Blue proliferation assay with PDL cells in contact with GuttaFlow, Endosequence BC, Pulp Canal Sealer EWT and AH Plus Jet, and with cells without root canal sealers (controls). After an incubation time of $96 \mathrm{~h}$, the root canal sealers Pulp Canal Sealer EWT and AH Plus Jet significantly inhibited cell growth compared to GuttaFlow, Endosequence BC, and the control cells.

Pulp Canal Sealer EWT and AH Plus Jet significantly inhibited cell growth $(\mathrm{p}<0.001)$. In contrast, incubation with GuttaFlow produced proliferation rates of the same order of magnitude as were found for the control group, and even promoted cell growth at $96 \mathrm{~h}$. The proliferation rate of the cells in contact with Endosequence $\mathrm{BC}$ was significantly lower $(\mathrm{p}<0.001)$ than of the controls, but significantly higher than cells in contact with Pulp Canal Sealer EWT and AH Plus Jet $(\mathrm{p}<0.001)$.

With the use of the ToxiLight ${ }^{\circledR}$ BioAssay, it is possible to measure the quantitative release of Adenylate Kinase (AK) from damaged cells. High relative luminescence units (RLU) indicate a high release of Adenylate Kinase, which again is an indicator for damaged cells. The RLU are measured after the cells have been incubated with the respective sealing agents for $24 \mathrm{~h}$. PDL fibroblasts without sealing material served as controls. Figure 3 shows the amounts of Adenylate Kinase released from the PDL fibroblasts incubated with the different sealing materials. Cells in contact with AH Plus Jet showed a significantly higher cytotoxicity than the controls and those incubated with the other sealing materials $(\mathrm{p}<0.001)$.

The application of Phallacidin/DAPI was utilized to visualize nucleus and cytoplasm (Figure 4A-D). This revealed that the PDL fibroblasts in contact with the sealing materials were partially altered in shape, appearing round with no visible cytoplasmic structures. Hardly any cells are visible in close proximity to Pulp Canal Sealer EWT and AH Plus Jet (Figure 3C-D). Similar results were obtained when the cells were stained with Calcein-AM/Ethidium homodimer II (Figure 4E-H). Ethidium homodimer II enters into cells through damaged membranes, binding to nucleic acids, thereby producing a bright red fluorescence in dead cells. The intact cell membrane of live cells is not permeable for Ethidium homodimer II. In close proximity to Pulp Canal Sealer EWT and AH Plus Jet, most of the cells are damaged, as can be observed by the red colour in nearly all cells close to the sealers (Figure 4G-H).

\section{Bacterial growth}

No antibacterial effect of GuttaFlow, EndoSequence BC or AH Plus Jet to E. faecalis DSM 20478 could be detected by scanning electron microscopy. After $24 \mathrm{~h}$ of incubation, on GuttaFlow, EndoSequence BC and $\mathrm{AH}$ Plus Jet short chains, micro-colonies or layers of the bacteria, covering the complete surface, can be seen (Figure 5A-B, D). In contrast, Pulp Canal Sealer EWT is more sparsely colonized and only short chains of the cells can be detected (Figure 5D). The visual analysis of the scanning electron micrographs of the root canal sealers incubated for $48 \mathrm{~h}$ with P. micra ATCC 33270 shows on GuttaFlow only few bacteria organized in micro-colonies, whereas EndoSequence BC is uniformly colonized by the bacteria (Figure 6A-B). On Pulp Canal Sealer EWT and AH Plus Jet only at a magnification of 2000 or higher a few bacteria can be detected (Figure 6C-D).

\section{Discussion}

The need for endodontic treatment is often associated with an inflammation caused by bacterial infection. For 


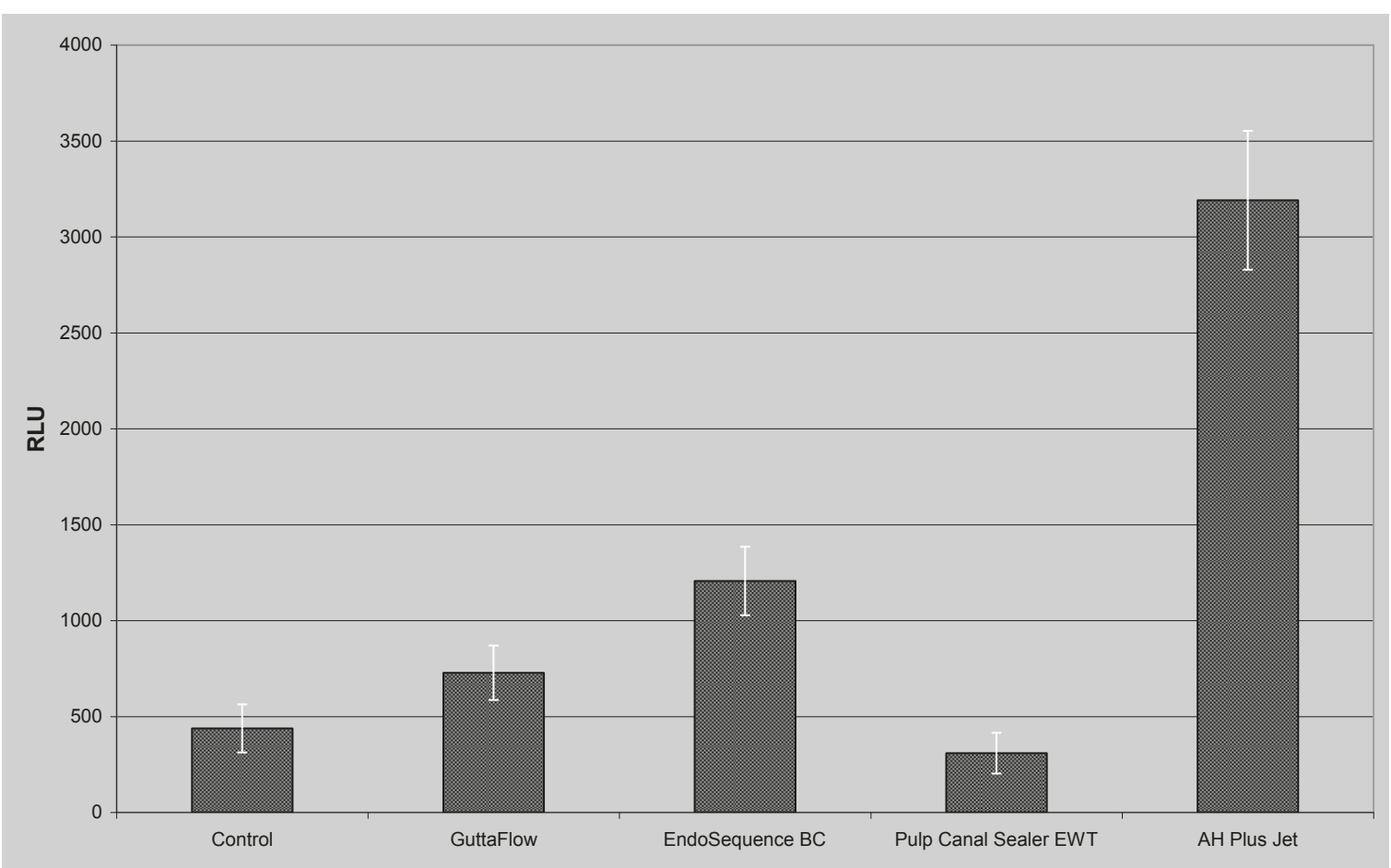

Figure 3 Results of the ToxiLight ${ }^{\circledR}$ BioAssay with PDL cells after $24 \mathrm{~h}$. The root canal sealer AH Plus Jet lead to a significantly higher release of Adenylate Kinase in comparison to the control cells and the other materials.

the successful root canal treatment, minimizing the possible inflammatory reaction caused by sealing materials, and suppressing bacterial growth are fundamental conditions. The goal of the endodontic treatment is to treat the teeth before a bacterial infection develops, and to use a biocompatible sealing agent. In case of an infection leading to pulp necrosis or of a bacterial contamination of the apical tissue, it is crucial for the outcome of the endodontic treatment to have a successful microbial elimination from the infected root canal system or
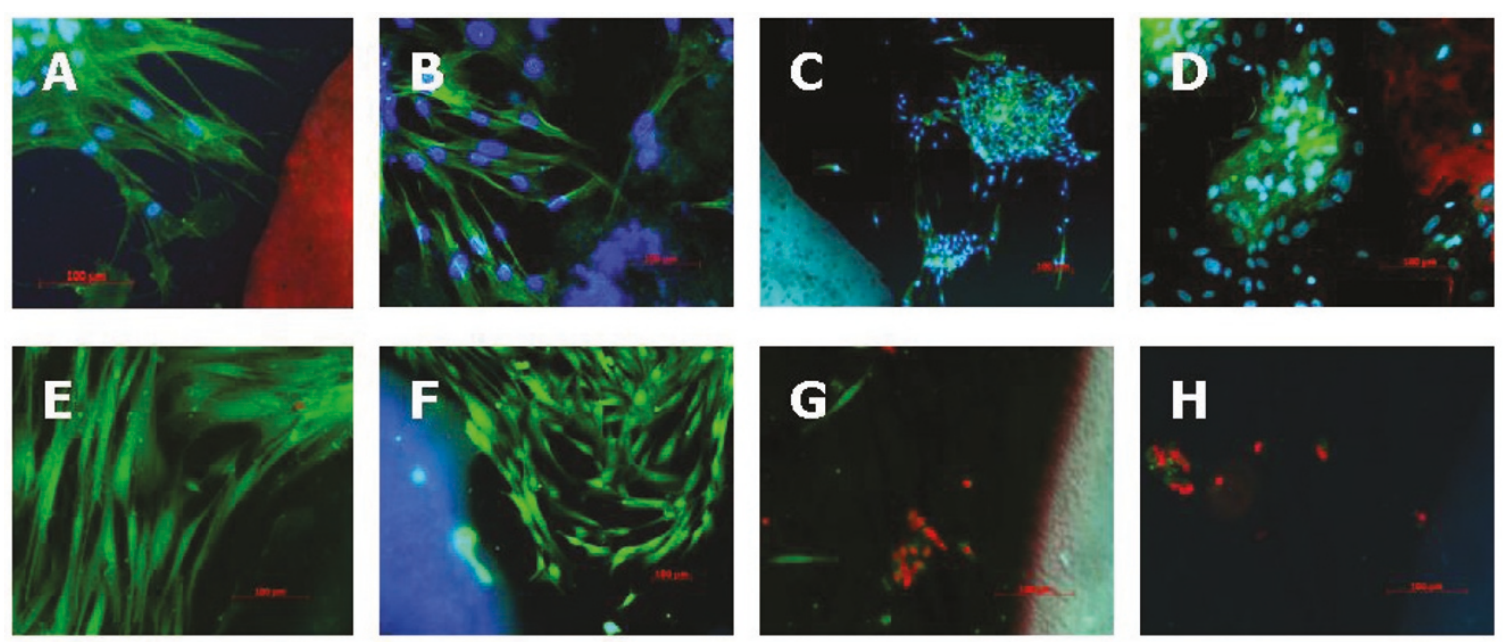

Figure 4 The reaction of the PDL fibroblasts to GuttaFlow, Endosequence BC, Pulp Canal Sealer EWT and AH Plus Jet, stained with Phallacidin/DAPI (magnification A, B and D $\times 200, C \times 100$, bar $=100 \mu \mathrm{m})(A-D$, upper panels) and with Calcein-AM/Ethidium homodimer II (magnification $\mathrm{E}, \mathrm{G}$ and $\mathrm{H} \times \mathbf{2 0 0}, \mathrm{F} \times \mathbf{1 0 0}$, bar $=100 \mu \mathrm{m})(\mathrm{E}-\mathrm{H}$, lower panels) is shown. DAPI- stains the nucleus blue, and Phallacidin counterstains the cytoplasm green. The intact membrane of live cells is not permeable for Ethidium homodimer II. 

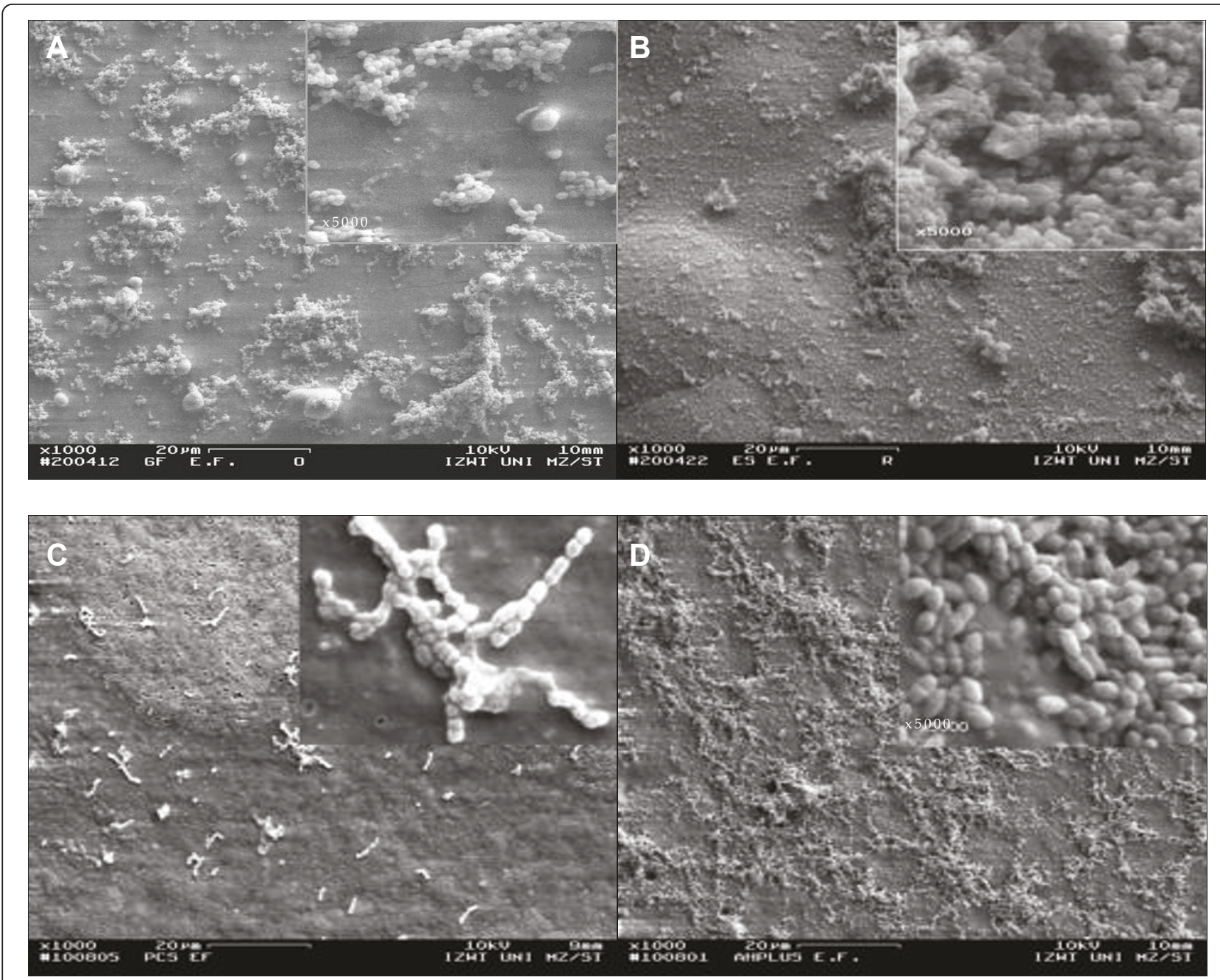

Figure 5 Scanning electron micrographs of E. faecalis DSM 20478 grown on a disc prepared from GuttaFlow (A), EndoSequence BC (B), Pulp Canal Sealer EWT (C) or AH Plus Jet (D) after $24 \mathrm{~h}$ of incubation (A-D $\times 1000$, insert $\times 5000$, bar $=20 \mu \mathrm{m}$ ).

to achieve a small enough number of microorganisms, which is clinically manageable [30]. It has also to be considered that in case of an inflammation caused by bacteria there will be a decrease of the $\mathrm{pH}$ in the periapical tissues, and thus there are special demands for the sealing agents [31]. The major task in reducing the bacterial load, concentrated in the apical region of the root canal, is achieved by the mechanical effects of instrumentation and the use of antimicrobial solutions for irrigation. Different studies have shown the essential role of chemo-mechanical procedures in eliminating the bacteria from the root canal system [32,33]. An antibacterial effect of root canal filling materials would be helpful, because if bacteria remain in dentinal tubules, this can serve as a reservoir for reinfection $[34,35]$. The bacteria chosen for this study were E. faecalis and P. micra (formerly $P$. micros). The former has been especially associated with endodontic failure, but has also been isolated from necrotic pulps. The latter organism, $P$. micra, has been isolated from asymptomatic and symptomatic primary endodontic infections, including abscesses as well as from endodontically treated teeth in need of re-treatment.

Calcium hydroxide is a well-described intra-canal material with an antibacterial effect, based on an alkaline $\mathrm{pH}$, which has been demonstrated in several studies $[36,37]$. This substance was shown to inactivate bacterial lipopolysaccharides in vivo [38], but it is not effective in destroying all bacterial species associated with root canal infections.

Therefore, in this study the biocompatibility as well a possible antibacterial effects of four different types of root canal filling materials was tested; GuttaFlow, a gutta percha based material, the well described epoxy resin based AH Plus Jet, the Pulp Canal Sealer EWT as a zinc oxide eugenol based sealer, and the newly 


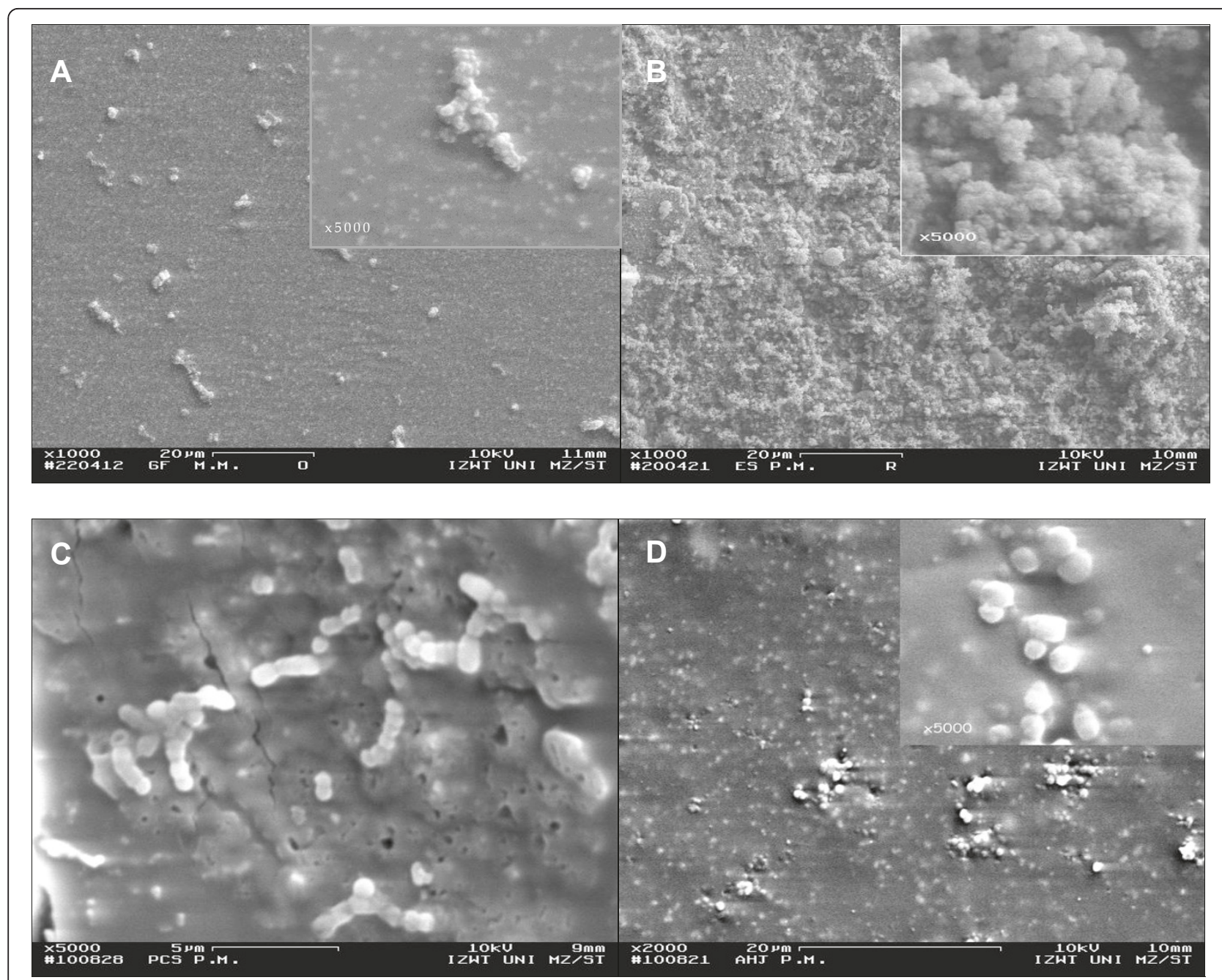

Figure 6 Scanning electron micrographs of $P$. micra ATCC 33270 grown on a disc prepared from GuttaFlow (A), EndoSequence BC (B), Pulp Canal Sealer EWT (C) or AH Plus Jet (D) after $48 \mathrm{~h}$ of incubation (A-B: Magnification $\times 1000$, insert $\times 5000$, bar $=20 \mu \mathrm{m}$; C: Magnification $\times 5000$, bar $=5 \mu \mathrm{m}$; D: Magnification $\times 2000$, insert $\times 5000$, bar $=20 \mu \mathrm{m})$.

developed EndoSequence BC with a calcium silicate composition. An inflammatory reaction to various root canal filling materials is a frequent complication, and the knowledge of these characteristics is essential for the clinical success. Profound knowledge about the properties and responses to the used sealers is necessary to be better prepared for dealing with serious complications associated with over-extrusion of the material into the peri-apical area. The results of the cell proliferation assay showed that Pulp Canal Sealer EWT and AH Plus Jet significantly inhibited cell growth, and showed a lower biocompatibility in comparison to GuttaFlow and Endosequence BC. In the study of Brackett et al. [39], a severe and consistent cytotoxic response for Pulp Canal Sealer and AH Plus Jet was also observed, even over a time of up to 8 weeks, when tested in three different cell lines.
AH Plus also had a cytotoxic effect on human pulp cells in vitro, and showed other previously reported proinflammatory characteristics [40], The demands made on sealing materials have been modified in recent years. The primary requirement for sealing agents is to obturate the root canal system and to establish a hermetic seal of the apical area of the root. To achieve this is desirable to inhibit the growth of the microorganisms i. e. mainly bacteria remaining within the cleaned root canal system [41]. On the other hand, root canal sealers are required to demonstrate a good biocompatibility and are not supposed to irritate the peri-radicular tissue. The sealing ability of the root canal filling material should allow an adequate peri-apical healing after placement.

This is relevant, because the extrusion of sealing materials into the apical region with the direct contact to the 
peri-apical tissue is a well-described complication in endodontic treatment. The over-extrusion of non-resorbable materials or materials with slow breakdown is regarded as a critical factor in the apical healing process.

It is known that when certain non-resorbable materials, especially in the maxilla, are extruded into the human sinus, or are in contact with connective tissue, these materials are capable of triggering chronic inflammations $[42,43]$. The present findings with established root canal filling materials showed the challenging requirements for sealers. In addition, the paradoxical postulation of Grossmann is emphasized that root canal filling materials is supposed to inhibit the growth of all microorganisms, but at the same time show a good biocompatibility and not irritate the peri-radicular tissue.

\section{Conclusion}

The present study shows that the materials Endosequence BC and GuttaFlow demonstrated a high biocompatibility, but had no antibacterial effect against $E$. faecalis. For P. micra a weak antimicrobial effect was observed with GuttaFlow. The sealers AH Plus Jet and Pulp Canal Sealer EWT showed a lower biocompatibility compared to Endosequence BC and GuttaFlow, but exerted a strong antimicrobial effect on $P$. micra.

\section{Acknowledgements \\ The authors whish to thank Claudia Darmstadt and Irmgard Schneiders for excellent technical assistance; Aslihan Gerhold-Ay from the Institute of Medical Biostatistics, Epidemiology and Informatics of the University Medical Centre, Johannes Gutenberg University Mainz, for advice concerning the statistical advice; Dr. Elmar Stender, Institute for Dental Material Sciences and Technology of the University Medical Centre, Johannes Gutenberg University Mainz, for the scanning electron micrographs. \\ Authors' contributions \\ BW, IW and AC carried out the study. IW performed the statistical analysis. BW, AC, IW and BB conceived of the study, and participated in its design and coordination. All authors read and approved the final manuscript}

\section{Competing interests}

The authors declare that they have no competing interests.

Received: 21 April 2011 Accepted: 10 August 2011

Published: 10 August 2011

\section{References}

1. Friedman S, Mor C: The success of endodontic therapy-healing and functionality. J Calif Dent Assoc 2004, 6:493-503.

2. Salehrabi R, Rotstein I: Endodontic treatment outcomes in a large population in the USA: an epidemiological study. J Endod 2004, 30:846-850.

3. Friedmann S, Abitbol S, Lawrence HP: Treatment outcome in endodontics: the Toronto Study. Phase 1: initial treatment. J Endod 2003, 29:787-793.

4. Dawson AS, Cardaci SC: Endodontics versus implantology: To extirpate or integrate? Aust Endod J 2006, 32:57-63.

5. Bratel J, Jontell M, Dahlgren U, Bergenholtz G: Effects of root canal sealers on immunocompetent cells in vitro and in vivo. Int Endod J 1998, 31:178-188.

6. Saunders WP, Saunders EM: Coronal leakage as a cause of failure in root canal therapy: a review. Endod Dent Traumatol 1994, 10:105-108.
7. Yamaguchi K, Matsunaga T, Hayashi Y: Gross extrusion of endodontic obturation materials into maxillary sinus: a case report. Oral Surg Oral Med Oral Pathol Oral Radiol Endod 2007, 104:131-134.

8. Nair PN: Pathogenesis of apical periodontitis and the causes of endodontic failures. Crit Rev Oral Biol Med 2004, 15:348-381.

9. Al-Khatar N, Kunzelmann KH, Hickel R: Apical leakage of new root canal sealers. J Dent Res 1995, 74:945.

10. Koulaouzidou EA, Papazisis KT, Beltes P, Geromichalos GD, Kortsaris AH: Cytotoxicity of three resin-based root canal sealers: an in vitro evaluation. Endod Dent Traumatol 1998, 14:182-185.

11. Neff $T$, Layman D, Jeansonne BG: In vitro cytotoxicity evaluation of endodontic sealers exposed to heat before assay. J Endod 2002, 28:12.

12. Bouillaguet S, Wataha JC, Tay FR, Brackett MG, Lockwood PE: Initial in vitro biological response to contemporary endodontic sealers. J Endod 2006, 32:989-992.

13. Brackett M, Martin R, Sword J, Oxford C, Rueggeberg FA, Tay FR, Pashley DH: Comparison of seal after obturation techniques using a polydimethylsiloxane-based root canal sealer. J Endod 2006, 32:1188-1190.

14. Schweikl H, Schmalz G, Federlin M: Mutagenicity of the root canal sealer AHPlus in the Amen test. Clin Oral Investig 1998, 2:125-129.

15. Azar NG, Heidari M, Bahrami ZS, Shokri F: In vitro cytotoxicity of a new epoxy resin root canal sealer. J Endod 2000, 26:462-466.

16. Cohen BI, Pagnillo MK, Musikant BL, Deutsch AS: An in vitro study of the cytoxicity of two root canal sealers. J Endod 2000, 26:4.

17. Sousa CJA, Montes CRM, Pasco EA, Loyola AM, Versiami MA: Comparison of the intraosseous Biocompatibility of AH Plus, Endo REZ, and Epiphany Root Canal sealers. J Endod 2006, 32:656-662.

18. Zielinski TM, Baumgartner JC, Marshall JG: An evaluation of Guttaflow and gutta-percha in the filling of lateral grooves and depressions. J Endod 2008, 34:295-298.

19. AlAnezi AZ, Jiang J, Safavi KE, Spanberg LS, Zhu Q: Cytotoxicity evaluation of endosequence root repair material. Oral Surg Oral Med Oral Path Oral Endod 2010, 109:122-125.

20. El Karim I, Kennedy J, Hussey D: The antimicrobial effects of root canal irrigation and medication. Oral Surg Oral Med Oral Pathol Oral Radiol Endod 2007, 103:560-569.

21. Weiss El, Shalhav M, Fuss Z: Assessment of antibacterial activity of endodontic sealers by direct contact test. Endod Dent Traumatol 1996, 12:179-184.

22. Cobankara FK, Altinöz HC, Ergani O, Kav K, Belli S: In vitro antibacterial activities of root-canal sealers by using two different methods. J Endod 2004, 30:57-60.

23. Bodrumlu E, Semiz M: Antibacterial activity of a new endodontic sealer against Enterococcus faecalis. J Can Dent Assoc 2006, 72:637.

24. Eldeniz AU, Erdemir A, Hadimli HH, Belli S, Erganis O: Assessment of antibacterial activity of EndoREZ. Oral Surg Oral Med Oral Pathol Oral Radiol Endod 2006, 102:119-126.

25. Miyagak DC, de Carvalho EM, Robazza CR, Chavasco JK, Levorato GL: In vitro evaluation of the antimicrobial activity of endodontic sealers. Braz Oral Res 2006, 20:303-306.

26. Slutzky-Goldberg J, Slutzky H, Solomonow M, Moshonov J, Weiss El, Matalon S: Antibacterial properties of four endodontic sealers. J Endod 2008, 43:735-738.

27. Zhang $H$, Shen $Y$, Ruse ND, Haapasalo M: Antibacterial activity of endodontic sealers by modified direct contact test against Enterococcus faecalis. J Endod 2009, 35:1051-1055.

28. Pinheiro CR, Guinesi AS, Pizzolitto AC, Bonetti-Filho I: In vitro antimicrobial activity of acroseal, prolifil and epiphany against Enterococcus faecalis. Braz Dent J 2009, 20:107-111.

29. Baer J, Maki JS: In vitro evaluation of the antimicrobial effect of three endodontic sealers mixed with amoxicillin. J Endod 2010, 36:1170-1173.

30. Siqueira JF Jr, Rôcas IN: Clinical implications and microbiology of bacterial persistence after treatment procedures. J Endod 2008, 43:1291-1301.

31. Nekoofar MH, Namazikhah MS, Sheykhrezae MS, Mohammadi MM, Kazemi A, Aseeley Z, Dummer PM: pH of pus collected from periapical abscesses. Int Endod J 2009, 42:534-538.

32. Bysrom A, Sundqvist G: The antibacterial action of sodium hypochlorite and EDTA in 60 cases of endodontic therapy. Int Endod J 1985, 18:35-40.

33. Rôcas IN, Siqueira JE: Comparison of the in vivo antimicrobial effectiveness of sodium hypochlorite and chlorhexidine used as a root canal irrigants. A molecular microbial study. J Endod 2011, 37:143-150. 
34. Wu MK, Dummer PM, Wesselink PR: Consequences of and strategies to deal with residual post-treatment root canal infection. Int Endod J 2006, 39:343-356.

35. Oguntebi BR: Dentine tubule infection and endodontic therapy implications. Int Endod J 1994, 27:218-222.

36. Tronstad L, Andreasen JO, Hasselgren G, Kristerson L, Riisi I: pH changes in dental tissues after root canal filling with calcium hydroxide. J Endod 1981, 7:12-21.

37. Esberard RM, Garnes DL Jr, del Rio CE: Changes in $\mathrm{pH}$ at the dentin surface in roots obturated with calcium hydroxide pastes. J Endod 1996, 22:402-405.

38. Tanomaru JM, Leonardo MR, Tanomaru Filho M, Bonetti Filho I, Silva LA: Effect of different irrigation solutions and calcium hydroxide on bacterial LPS. Int Endod J 2003, 36:733-739.

39. Brackett MG, Messer RL, Lockwood PE, Bryan TE, Lewis JB, Bouillaguet $S$, Wataha JC: Cytotoxic response of three cell lines exposed in vitro to dental endodontic sealers. J Biomed Mater Res B Appl Biomater 2010, 95:380-386.

40. Camargo CH, Camargo SE, Valera MC, Hiller KA, Schmalz G, Schweikel H: The induction of cytotoxicity, oxidative stress and genotoxicity by root canal sealers in mammalian cells. Oral Surg Oral Med Oral Pathol Oral Radiol Endod 2009, 108:952-960.

41. Grossman LI: Root canal therapy. Kimpton, London; 1940.

42. Batur YB, Ersev H: Five-year follow-up of a root canal filling material in the maxillary sinus: a case report. Oral Surg Oral Med Oral Pathol 2008, 106:e54-56.

43. Zmener O: Tissue response to a new methacrylate-based root canal sealer: Preliminary observations in the subcutaneous connective tissue of rats. J Endo 2004, 30:348-351.

doi:10.1186/1746-160X-7-15

Cite this article as: Willershausen et al: In vitro analysis of the cytotoxicity and the antimicrobial effect of four endodontic sealers. Head \& Face Medicine 2011 7:15

\section{Submit your next manuscript to BioMed Central and take full advantage of:}

- Convenient online submission

- Thorough peer review

- No space constraints or color figure charges

- Immediate publication on acceptance

- Inclusion in PubMed, CAS, Scopus and Google Scholar

- Research which is freely available for redistribution

Submit your manuscript at www.biomedcentral.com/submit 